growing that the evils from alcohol must be taken up as a great sanitary and medical topic. The recognition of the med. ical side of this evil, and the physical means required to cope with it, showed a great advance.

While this gathering was not particularly notable for new facts, it gave greater eminence to old theories and greater prominence to the need of more accurate study of this evil. There was something very stimulating in this hearty union of all classes for the study of the evils of alcohol ; while many different' societies and church associations have conflicting theories of the causes of and remedies for alcoholism, they all argue that certain general physical causes are traceable to it and can be removed.

The leading continental physicians and teachers are very emphatic in calling alcoholism a disease and urging medical treatment. The continental physicians appear to have much influence with laymen on matters of social and sanitary science, and hence are put forward prominently as leaders.

In the sectional meetings physicians were given a deferential hearing, more so than clergymen, and several French and Swiss physicians displayed unusual oratoric powers. A congrese of this kind would be a great help to clear away the con. fusion which hangs over the subject in this country. Hundreds of physicians would welcome a general scientific study of this subject, and a public sentiment that would encourage efforts to find causes and remedies for this evil.

The foolish unfounded theories which cling to this topic are fast disappearing in Europe, and wine and beer drinking is as freely condemned as the excessive use of stronger spirits. Physicians, above all others, should teach the facts, and not be taught by laymen, or fear the popular opinions of persons who have little or no accurate knowledge.

T. D. Crothers, M.D.

\section{Competitive Examinations.}

Cincinnati, Ohio, May 2, 1899.

To the Editor:-The letter of Dr. Bayard Holmes in last week's. Journal (see April 29, p. 927) meets with my hearty approval. I am and long have been convinced that a written examination, as an exclusive means of determining qualifica tions in any departmont, is fallacious. As a means of determining the ability of candidates for hospital interneships, it is strik ingly defective. I have no objection to written examinations as one way of finding out what a person may know, but they ought to occupy a subordinate place in the general plan of investigation. The reform method should embrace all that is now included in the written examinations, plus test exercises in the laburatories, in the mortuary and at the bedside of the sick. When this comprehensive plan is adopted, examining bodtes may ascertain approximately what candidates may or may not know, and that is more than can be said of the present method.

Another pernicious feature of the present system is the preliminary coaching to which intending applicants for hospital positions are subjected. If the mere cramming process were all of it, it would be bad enough, but it is not. In more than one city of my knowledge students are requested at the time of matriculation to declare their intention of going in for interneships, and great rivalry existe between schools to score the larg est winninge before these more or less farcical concerns. Students who enter for the race are coached from the beginning, not with the object of giving them a broad, symmetric and logic medical education, but with the object of making them familiar with the peculiar views of individual members of the examining body. Lists of old questions are a part of the stock in trade of professional coachers. Students are encouraged to. miss regular lectures that may not have a direct and apparent bearing on the prospective examination. They are then per mitted, in certain cities, to go up for the examinations at the end of their junior year, returning to their respective schoole for the finals, a twelvemonth later. They then get their diplomas after an actual attendance at the colleges, of probably less than two years, all told. When they go to their State licensing bodies for registration they all present certificates of actual attendance on four full courses of lectures in four separate years! How can these things be? Who knows? But what it is, and this that is, is a matter for the licensing bodies. It would not be in the least malapropos on the program of the coming meeting of the Confederation of State Examining and Licensing Bodies. It might not be amiss if Dr. Bayard Holmes' own organization, the Association of American Medical Colleges, would also throw its search-light in this direction. It would certainly be fruitful of better results than the recent endeavor to ostracize first-class medical college men whoconducted threeyear schools and were honest enough to say so.

R.

\section{Revision of Pharmacopeia.}

Philadelphia, May 1, 1899.

To the Editor:-In accordance with instructions given by resolutions passed at the National Convention for Revision of the Pharmacopeia of the United States of America, held in Washington, in 1890, I herewith give notice that a general convention for the revision of the pharmacopeia of the United States of America will be held in the City of Washington, D. C., beginning on the first Wednesday in May, 1900 . It, is requested that the several bodies represented in the convention of 1880 and 1890, and also such other incorporated State medi. cal and pharmaceutic associations, and incorporated colleges of medicine and pharmacy, as shall have been in continuous oper ation for at least five years immediately preceding this notice, shall each elect delegates, not exceeding three in number; and that the surgeon-general of the army, the surgeon-general of the navy, and the surgeon-general of the marine-hospital service shall appoint, each, not exceeding three_medical officers to attend the aforesaid convention.

It is desired that the several medical and pharmaceutic bodies, and the medical departments of the Army, Navy and Marine-Hospital Service, shall transmit to me the names and residences of their respective delegates, so soon as said delegates shall have keen appointed, so that a list of the delegates to the convention may be published, in accordance with the resolutions passed at the 1890 convention for the revision of the pharmacopeia, in the newspapers and medical journals in the month of March, 1900.

Finally, it is further requested that the several medical and pharmaceutic bodies concerned, as well as the medical departments of the army, navy and marine-hospital service, shall submit the present pharmacopeia to a careful revision, and that their delegates shall transmit the result of their labors to Dr. Frederick A. Castle, 51 West Fifty-eighth Street, New York City, secretary of the Committee of Revision and Publication of the U. S. Pharmacopeia, at least three months before May 2, 1900, the date fixed for the meeting of the convention. H. C. Wood, M.D.

President of the National Convention for Revising the U.S. Pharmacopeia, held in Washington, D. C., A.D. 1890.

\section{No Smallpox in Uniontown. \\ Uniontown, PA., May 6, 1899.}

To the Editor:-Under the caption of "Medical News," in the Journal of May 6, you state Uniontown has eight cases of smallpox and that the government has ordered all mail fumigated, and that the freight and traffic business has been suspended.

I have been practicing medicine at this place for the past fifteen years and during all that time this is the first that $I$ have ever heard that we had any smallpox. Allow me to correct 